

\title{
Aby Warburg y el ritual de las imágenes
}

\section{Aby Warburg and the Ritual of Images}

\section{Dr. Hernán Ulm*}

\begin{abstract}
Resumen
En este trabajo buscamos una aproximación entre la obra de Aby Warburg y concepto de ritual según la perspectiva abierta por Van Gennep y Turner. Esta aproximación nos permitirá pensar las imágenes (Pathosformel) como experiencias de "pasaje". En este sentido, queremos mostrar que una imagen pone en escena un "drama" como parte de un "proceso ritual" (Turner). Si, como dice Warburg, las imágenes sirven para hacer frente a las angustias y conflictos a través de los que la humanidad se ha hecho posible, creemos que podemos re-pensar nuestras relaciones con ellas como índices de tales "ritos de pasaje". De esta forma las imágenes pueden pensarse como marcas de la abertura a la "communitas" (Turner) y, al mismo tiempo, como "restauración" del orden que garantiza un "espacio de pensamiento" (Denkraum) indispensable para la configuración de la cultura.
\end{abstract}

\section{Palabras clave}

Imágenes. Ritual. Communitas. Memoria. Drama.

\begin{abstract}
In this paper we intend to associate the works of Aby Warburg and the concept of ritual according to the perspective opened by Van Gennep and Turner. This approach will allow us to think the images (Pathosformel) as experiences of "passage". In this sense, we want to show that an image stages a "drama" as part of a "ritual process" (Turner). If, as Warburg says, images serve to deal with the anguishes and conflicts through which humanity has become possible, we believe that we can rethink our relationships with them as indexes of such "rites of passage". In this way, images can be thought of as marks of the opening to the "communitas" (Turner) and, at the same time, as "restoration" of the order that guarantees an indispensable "space of thought" (Denkraum) for the configuration of culture.
\end{abstract}

\section{Keywords}

Images. Ritual. Communitas. Memory. Drama. 


\title{
Definir el arte. Una heurística dispersa
}

Lo primero que hay que aceptar, si queremos jugar con esta idea, es que la intensidad de una experiencia supera, coexiste y hasta excede al individuo que la vive. Una idea que no es ajena a las investigaciones de Aby Warburg sobre lo que llamaba Pathosformel, representaciones de estados extremos en los que intervienen la violencia y el éxtasis, conectados entre sí gracias a una tensión extrema que los emparenta más allá de la naturaleza misma de cada representación: la foto de un crimen en Sicilia, la representación del estado de abandono de una escultura erótica o una pintura religiosa. Como Warburg, Klossowsky ve en esa relación, independientemente de la naturaleza misma de la figura, un acto de abolición del tiempo. De otra manera, y a propósito de otros problemas, $\mathrm{R}$. Sheldrake habla del ritual en estos términos: 'A través de la celebración consciente de actos rituales, y celebrándolos en lo posible del mismo modo en que otros los celebraron antes, los participantes entran en "resonancia cósmica" con quienes ejecutaron los mismos rituales en el pasado. Entonces el tiempo se desmorona y se hace presente, inevitablemente, esa suerte de "comunidad transtemporal" formada por todos aquellos que alguna vez celebraron ese mismo ritual" (Ruiz, 2013: 190-191, subrayado nuestro).

No hay, tal vez, nada más simple que evitar comprometernos con una definición de arte. Sin embargo, por ello mismo, no hay, tal vez, tarea más urgente. Al fin y al cabo, la experiencia que bajo ese nombre se recubre no deja, desde hace más de un siglo, de sobrevivir a los intentos por expulsarla de la cartografía de nuestro pensamiento, como esos viejos fantasmas que habitan en las casas familiares y que, evitando todo exorcismo, se aparecen de tanto en tanto para recordarnos que ellos están allí, en el límite entre lo vivo y lo muerto, ni vivos ni muertos, casi vivos y casi muertos, para señalar el umbral, el momento de un pasaje por el cual una cosa se transforma en otra (Gilles Deleuze [2003: 301], citando a Malraux - ¿Qué es un acto de creación? -, decía que el arte es tal vez lo único que en verdad resiste a la muerte, incluso, diríamos aquí, resiste a su propia muerte).

A lo largo de sus artículos, Aby Warburg fue desplegando diversos modos de aproximación a la cuestión del arte. Sin embargo esos intentos, en sus múltiples sentidos, develan un esfuerzo que quedaría al fin inconcluso, y parecen poder caracterizarse según una tendencia general: escapar de todas las tentaciones esteticistas e historicistas que, desde Giorgio Vasari y Johann J. Winckelmann, definían los contornos del arte (como si éste fuera un objeto especial, portador de los valores de belleza en los que se transparentaban los ideales de una Cultura), para elaborar una modulación del tiempo que permitiera arrancarnos de la economía regulada por la cronología. En este sentido, desde el comienzo de su trabajo, Warburg establece claramente las condiciones de su rechazo. Así lo podemos leer en las notas preparatorias de a la conferencia El ritual de la serpiente:

\begin{abstract}
¿Por qué fui? ¿Qué me atrajo? Desde afuera, en la superficie de mi consciencia, diría que, como yo experimentaba tal repugnancia hacia el vacío de la civilización del Este de Norteamérica, decidí huir hacia las cosas reales y hacia el saber, a la aventura (...) Además estaba asqueado de la historia del arte estetizante. La contemplación formal de la imagen, no considerada como un producto biológicamente necesario entre la práctica religiosa y artística (cosa que comprendí recién más adelante) me parecía que daba lugar a parloteos tan estériles que después de mi viaje a Berlín, durante el verano de 1896, traté de volver a mis estudios de medicina (Warburg apud Michaud, 2018: 213).
\end{abstract}

Se trata, desde aquel temprano y mítico viaje y desde el texto tardío con que se conoce la conferencia, de "curarse", de volverse prolífico, de huir de la repugnancia (de eso que re-pugna) y del vacío de la civilización (estéril y decadente) hacia las cosas reales. De hacer de las imágenes una instancia de "cura" y del arte una experiencia de "salud". Casi treinta años pasan entre los dos acontecimientos (el 
acontecimiento del viaje y el acontecimiento de la escritura de la memoria del viaje). En el medio se despliegan un abanico de textos (notas, diarios, artículos y conferencias) que instigan a una redefinición integral de los principios de aproximación a un campo, todavía, en ese momento, incierto. Ese rechazo inicial es, como sabemos, lo que da nacimiento a las varias dispersiones con que el teórico alemán irá inventando esa cartografía que, desde entonces, conocemos como iconología, entendida como un modo novedoso de establecer nuestras relaciones con aquello que seguiremos llamando arte, aún a costa de tener que definir una y otra vez lo que entendemos por esta palabra (habría por ello que explicitar que en el nacimiento de la iconología está contenido su rechazo, su asco y su repugnancia a la historia del arte, y esto pese a las restauraciones que la disciplina conoció de la mano de Erwin Panofsky o Ernst Gombrich: una iconología de las imágenes difícilmente pueda convertirse en Historia del Arte). En este sentido, el esfuerzo warburguiano establecerá una doble estrategia: por un lado, nos exigirá pensar la deriva del arte "más allá de las cuestiones de gusto" (Ulm, 2014) y, por otro lado, nos animará a pensar una temporalidad que se aleja de las economías causales y acumulativas heredadas (y reforzadas) de y por la propia disciplina. Las preguntas parecen sencillas: ¿qué son las obras de arte cuando ya no la pensamos desde los principios idealistas de una ciencia que se configuró como guardiana de las fronteras de las buenas formas de la cultura occidental? ¿y que pasa con la forma histórica del tiempo cuándo renunciamos a la economía de la línea recta? Las respuestas warburguianas a estas preguntas son ya bastante conocidas: las obras de arte, retiradas de ellas toda pretensión y todo Juicio sobre su Belleza, se manifiestan como imágenes. Por ello deberemos aproximarnos a ellas según un conjunto de cuestiones que nada tienen que ver con los principios que organizaban una ciencia de lo bello. En vez de tales "estériles parloteos", nos preguntaremos por la exigencia que hizo nacer una imagen y por la fuerza que la hace sobrevivir, por la potencia de la que ella la imagen es portadora y por la energía que en ella se dispara cuando entra en contacto con un presente que la reclama. De la misma forma, una vez que la Historia es destituida de la soberanía del Logos, aparecerá inscripta en las imágenes una Memoria transindiviudal y colectiva, fórmula de un tiempo intensivo (como bien lo expone Raúl Ruiz en el epígrafe a este trabajo) que no cesa de reelaborarse una y otra vez como aprehensión de un sentido que se debe siempre volver a inventar. De tal manera, lejos de ser el Relato del Espíritu reconociéndose en sus obras, la iconología será un diagnóstico de los conflictos, las tensiones irreconciliables (que pugnan y repugnan) en el espacio siempre abierto de la Cultura. Quizás, una de las cuestiones más complejas del pensamiento warburguiano sea su invitación explicita a renunciar a la línea recta, y esto porque el pensador alemán no solo abandona la línea recta del tiempo (esa "vía de mano única" del positivismo decimonónico) (Benjamim, 2014) en que se alojaba un destino seguro de la Historia, sino también porque deja de lado la línea recta de la ortodoxia de una disciplina que marcaba de antemano los contornos de los objetos con que debía trabajar:

Con la investigación completamente provisional de un tema concreto, pretendía salir en defensa de una ampliación metodológica de las fronteras de nuestra Historia del Arte, tanto por lo que se refiere a su ámbito material como al espacial. Hasta el momento, una serie de categoría evolutivas generales, del todo insuficientes, han impedido a la Historia del Arte disponer de su propio material para constituir una 'psicología histórica de la expresión humana' que aún no ha sido escrita (...) Con el método que he utilizado en la interpretación de los frescos del Palazzo Schifanoia de Ferrrara espero haber mostrado que sólo es posible iluminar los grandes procesos evolutivos esforzándonos en aclarar detalladamente un punto oscuro concreto, y esto a su vez sólo es posible con un análisis iconológico que, rompiendo el control policial que se ejerce sobre nuestras fronteras metodológicas, contemple la Antigüedad, el Medioevo y la Edad Moderna como épocas interrelacionadas, e interrogue, tanto a la obras de arte autónomo como a las artes aplicadas considerándolas como documentos expresivos de idéntica relevancia (Warburg, 2015: 434). 
No decimos nada nuevo: romper con un objeto es partir las aguas con el método que lo circunscribía. $\mathrm{Y}$, en el mismo sentido, romper con un método es abrirse a la experiencia de una objetividad que se debe constituir. Pero esta hendidura, esta cesura que se traza es tal vez mucho más pregnante ya que Warburg no busca establecer una "nueva ciencia" (con o sin nombre, poco importa) ni una disciplina: la iconología no constituye un cuerpo, no es un método, no es un principio de investigación detectivesco. Es si se quiere una operación que trabaja en el interior de sí misma intentando explorar el límite en el que se reorganiza lo que previamente se ha desorganizado (yendo así de los "monstruos" a los "astra", es decir, de los terrores a los cielos, de la oscuridad de las tinieblas a la luz de las estrellas). La iconología, podemos decir, es una "experimentación" con las imágenes (tal vez en el sentido en que [Foucault, 1996] hablaba del libro como una "experimentación"): en ese sentido, no dice qué es una imagen, no dice qué es el arte sino que hace la experiencia de la imagen, trabaja en la experiencia con el arte. Algo cercano, en ese sentido, a la estructura de la transgresión analizada por Georges Bataille (como lo muestra Georges Didi-Huberman, especialmente en La semejanza informe): en la medida en que la iconología no es un cuerpo disciplinar, ella no deja de transgredirse a sí misma buscando unas formas que se deshacen a cada instante. Por ello, se multiplican en los textos warburguianos los esfuerzos por demarcar lo que, por mi parte, quisiera llamar una heurística de la disparidad, que nos exige pensar una y otra vez las formas de construcción de objetividades que no están dadas (las obras de arte, las imágenes, las Pathosformel no son cosas cuya evidencia se presente sin esfuerzo) sino que se deben construir (cercano, en esto a Foucault quien afirmaría luego que no existen ni objetos ni sujetos sino prácticas discursivas y no discursivas que construyen umbrales desde donde se delimitan objetividades y subjetividades ${ }^{1}$ ). Arriesgando una anacronía conceptual (de esas que tanto nos ayudó a imaginar Warburg mostrando que el tiempo no se deja gobernar por una sola economía) podríamos decir que la heurística warburguiana es un esfuerzo de construcción interseccional, en la medida en que va configurando un campo de trabajo que no se identifica con ningún objeto (y que va de la antropología de James Frazer al pensamiento nietzscheano, de la biología darwinista a las teorías del lenguaje decimonónicas). Como resultado de ese esfuerzo de construcción, el arte ya no puede ser identificado con una "obra", una "cosa" portadora de "valores" que transmite una identidad (cualquiera esta fuera). En este sentido, tal vez sea esto lo primero que podamos decir: en el arco que recorremos junto a las dispersiones warburguianas, el arte es un campo de exploración y de tensiones a través del cual hombres y mujeres arrojados a una existencia improbable crean formas de mediación que les permiten tomar distancia de sus propias angustias y hacerse un mundo vivible. El comienzo de la Introducción al Atlas lo explicita:

El acto de interponer una distancia entre uno mismo y el mundo exterior puede calificarse de acto fundacional de la civilización humana; cuando este espacio interpuesto se convierte en sustrato de la creación artística, se cumplen las condiciones necesarias para que la conciencia de la distancia pueda devenir en una función social duradera -que el ritmo de puesta en vibración de la materia y el reposo de la misma en la sofrosyne presenta como un ciclo entre la cosmológica de las imágenes y la de los signos -, la suficiencia o el fracaso de la cual como instrumento espiritual orientador determina el destino de la cultura humana. Al hombre que como artista se debate entre las concepciones religiosa y matemática del mundo viene a ayudarle de forma característica la memoria tanto de la personalidad colectiva como la del individuo: no creando sin más un espacio para el pensamiento, pero sí fortaleciendo en los polos extremos del comportamiento psíquico la tendencia a la contemplación serena o a la entrega orgiástica (Warburg, 2010: 3).

El arte resultaría así un campo de operaciones 0 , mejor, una zona de combate, en el que se dan cita fuerzas antagonistas y en el que se crean las condiciones mínimas para que el existente humano se cree su propio espacio de vida. No habría vida humana posible sin la persistencia de las imágenes como 
mediadores simbólicos entre nuestra existencia y la del mundo. Pero, como lo muestra bien DidiHuberman, el símbolo no unifica lo disperso: es la escena de la dispersión. El arte sería así un campo de distribución en el que las imágenes que sobreviven a su propio presente operan como mediadores entre fuerzas dispares y en conflicto que dan cuenta de las maneras diversas en que hombres y mujeres han intentado aprehender las contrariedades de la existencia. Despojado de sus valores esteticistas el arte se revela como el espacio en que se construye una ethesis, una lógica de lo sensible que permite que se aparezca, en ese espacio que el mismo abre para pensar (Denkraum), los vestigios de una memoria colectiva que no cesa de reapropiarse de sí misma. Un campo, que, en definitiva, presenta a las imágenes como un ritual. Un ritual de imágenes.

\section{Las imágenes como procesos rituales: drama, liminaridad y communitas}

La communitas tiene también un aspecto de potencialidad, de ahí que se dé frecuentemente en el modo subjuntivo. Las relaciones entre seres totales son generadoras de símbolos, metáforas y comparaciones; sus productos son el arte y la religión más que las estructuras políticas y legales. Bergson vio en las palabras y escritos de los profetas y grandes artistas la creación de una 'moralidad abierta', que era a su vez expresión de lo que él llamaba l'élan vital, o impulso vital evolutivo (Turner: 133, subrayado nuestro).

La teoría del ritual ha atravesado el siglo XX según diferentes formulaciones y alcanzando diversos campos. Como lo han mostrado muchos teóricos, en la confluencia entre los estudios de la performance (llegados desde el ámbito de las artes escénicas y del cuerpo) y los estudios sobre lo performativo (a través de los aportes de la filosofía del lenguaje angloamericana de la segunda mitad del siglo XX), el concepto de "ritual" ha sido releído y ampliado de modo tal que su extensión llega mucho más allá del ámbito de la religión y de lo sagrado, recubriendo cualquier tipo de conducta o proceso social, sea de tipo "ordinario" o "extraordinario". Así lo afirma André Le Breton:

O homem participa do vínculo social não só por sua sagacidade e suas palavras, por seus empreendimentos, mas também por uma série de gestos, de mímicas que concorrem à comunicação, pela imersão no seio dos incontáveis rituais que escandem a cotidianidade (Le Bretón, 2016: 12-13).

El trabajo inaugural de Arnold Van Gennep (1908) ya anticipaba que una teoría de los rituales de paso podía extenderse mucho más allá del ámbito restringido de su propio campo de interés: "Creo, sin embargo, que mi demostración será suficiente, y ruego al lector que lo compruebe aplicando el esquema de los ritos de paso a los hechos de su ámbito personal de estudio" (Van Gennep, 2013: 18).

Como lo indicara Marcel Mauss (1979), un ritual es un conjunto de reglas prácticas, de carácter colectivo, que tienen por fin la producción de una creencia intersubjetivamente compartida, y por el cual se modifica un estado de cosas (una transformación en el estatuto de los agentes que lo practican que supone también una mutación del mundo en que esa práctica tiene lugar). En este sentido, un ritual tiene por fin asegurar la cohesión de los límites de una comunidad y de los individuos que la componen en cada uno de las diferentes fases por las que atraviesa su vida. Ya Van Gennep, indicaba este aspecto central de los rituales por los que estos se constituyen en reguladores de las conductas de una comunidad y que acercan su teoría a algunas formulaciones warburguianas en relación a las imágenes:

La vida individual, cualquiera que sea el tipo de sociedad, consiste en pasar sucesivamente de una edad a otra y de una ocupación a otra. Allí donde las edades como las ocupaciones están separadas, este paso va acompañado de actos especiales, que por ejemplo en el caso de nuestros oficios constituyen el aprendizaje, y que entre los semicivilizados consisten en ceremonias. (...) Todo cambio en la situación de un individuo comporta 
acciones y reacciones entre lo profano y lo sagrado, acciones y reacciones que deben ser reglamentadas y vigiladas a fin de que la sociedad general no experimente molestia ni perjuicio. Es el hecho mismo de vivir el que necesita los pasos sucesivos de una sociedad especial a otra y de una situación social a otra: de modo que la vida individual consiste en una sucesión de etapas cuyos finales y comienzos forman conjuntos del mismo orden: nacimiento, pubertad social, matrimonio, paternidad, progresión de clase, especialización ocupacional, muerte. $Y$ a cada uno de estos conjuntos se vinculan a ceremonias cuya finalidad es idéntica: hacer que el individuo pase de una situación determinada a otra situación igualmente determinada (Van Gennep, 2013: 20-21, subrayado nuestro).

En este sentido, un ritual tiene efectos de vigilancia, control y regulación sobre las conductas de aquellos que los practican. Su fin es lograr un vínculo entre los agentes que componen la comunidad - y que se reconocen formando parte de la misma como consecuencia de los actos rituales que comparten. En este sentido, podríamos pensar que los rituales configuran prácticas de gobierno (Foucault, 1994), que establecen un conjunto de procedimientos para dirigir las conductas de los otros. No deberemos alejarnos mucho de Warburg para comprender que las imágenes cumplen funciones análogas a las de los rituales: bien sabemos que las imágenes no son para él meras ilustraciones o representaciones sino manifestaciones de un deseo que expresa la pertenencia a un vínculo social: "Las imágenes de los arcones y de los tapices representan la vida social de una cultura satisfecha de sí misma que se da a conocer, con todo lujo de detalles, en el tono coloquial propio de una canción popular cortesana" (Warburg, 2005: 230). Es por y a través de las imágenes que los miembros de una comunidad se reconocen y es por y a través de las imágenes que los miembros de una sociedad actúan: las imágenes son portadoras de una fuerza (performance) que exige de nosotros un conjunto de acciones, de respuestas, de interrogaciones sin los cuales el vínculo social sería imposible. Esa performance de las imágenes es la que las iguala a los rituales: "Es claro que éste es el significado de todo el ceremonial. Las sucesivas ceremonias demuestran que estas serpientes iniciadas y consagradas, en mágica comunión con los indios, son las mediadoras solicitantes y provocadoras de la lluvia. Son entonces, como santos de la lluvia vivientes y zoomórficos" (Warburg, 2004: 46). Así sucede como los Hopi y sus complicados rituales de la serpiente, el largo viaje migratorio de los dioses olímpicos hasta el palacio del duque de Ferrara no tiene otro fin que cubrir el vacío de una rueda (como lo dice Turner al respecto de la metáfora de Lao-Tsé que veremos a continuación) que se revela como ausencia de sentido ante la muerte. Tanto el duque de Ferrara como los hombres y mujeres Hopi buscan resistir, a través de sus gestos y sus imágenes, tratan de poner distancia a aquello que los amenaza: el duque a la transitoriedad de un tiempo que se le escapa, los Hopi a las inclemencias de un desierto que les prohíbe el agua: "La danza de las serpientes en Walpi constriñe a la propia serpiente a fungir como elemento mediador (...) No cabe duda de que este arrojamiento mágico tiene el objetivo de obligar a la serpiente a obrar como propiciadora de los rayos y generadora de la lluvia" (Warburg, 2004: 46). Y en Ferrara, las imágenes no están allí para ilustrar una Historia: ellas, desde un pasado que sobrevive a su presente, actúan sobre nosotros estableciendo pautas de conducta que deberemos seguir si queremos obtener algún tipo de resultado específico: "La astrología no es en el fondo sino un fetichismo onomástico proyectado al futuro: por ejemplo, de acuerdo con las cualidades que el mito atribuye a la diosa venus, aquél nacido en el mes de abril sería iluminado por su planeta y viviría para el amor y los placeres fáciles de la vida" (Warburg, 2015: 417). Así, el duque de Ferrara hace pintar una cartografía del tiempo según la cual las imágenes orientan su futuro y deciden por él las conductas que debe asumir para realizar su destino. Las imágenes, como los objetos rituales, actúan. Y actúan orientándonos, ofreciéndonos seguridad: diríamos que a través de ellas podemos domesticar la muerte y asegurarnos las fases de un paso hacia otra vida. Las imágenes son una performance visual por la cual se transforma el estado de cosas en el mundo y nuestro propio modo de existencia: nuestra subjetividad ante el mundo se ve alterada, modificada, en la confrontación con las imágenes. Si como dice Didi-Huberman (2006) ante la imagen 
estamos ante el tiempo, también podemos decir que ante la imagen estamos ante una performance que nos obliga, que nos orienta, que le da sentido y organiza nuestra existencia: esa es, (lo vimos más arriba) la función primordial de las imágenes: ser mediadoras y hacernos pasar, organizar un pasaje a través del cual transitamos entre la vida y la muerte; de allí su apariencia de fantasmas que sobreviven al tiempo. Por ello, ante la imagen estamos ante un umbral, un pasaje, un rito de paso, como decíamos con Van Gennep: pensemos, por ejemplo, en las ascensiones a través de las escaleras en la que se regula el paso de uno a otro mundo y al estudio del surgimiento del retrato como mediación entre dos mundos al que se consagra Warburg en El arte del retrato y la burguesía florentina. Del sótano de la iglesia emergen las figuras de los hijos del comitente llevados a la luz por la mano segura de su maestro, tanto como en los indios Hopi las escaleras señalan un sistema de ascensos y descensos que señalan el paso de y hacia lo doméstico:

El ser humano, que ha dejado de caminar en cuatro patas para hacerlo en posición erecta, y que por lo tanto necesita de un instrumento para vencer la fuerza de gravedad cuando mira hacia arriba, ha inventado la escalera para ennoblecer sus deficiencias con respecto al animal. El hombre que a la edad de dos años aprende a caminar, percibe la felicidad del escalón porque, como criatura que tiene que aprender a andar, recibe al mismo tiempo la gracia de poder elevar la cabeza (Warburg, 2004: 25).

A través de las acciones y de las palabras que los expresan, los rituales y las imágenes (como los calendarios germánicos que organizan la tensión del naciente protestantismo analizado por Warburg) no son verdaderos o falsos (por relación a un objeto que ellos deberían alcanzar y describir) sino eficaces o ineficaces en la producción de creencias colectivas (de las que dependerá, en este caso, el porvenir de la religión fundada por Martin Lutero). No otro sentido tiene la larga cita final (tomada de Johann W. Goethe) con que acaba el artículo (y en el que parece resonar la divisa benjaminiana [Benjamin, 1989], "la diferencia entre magia y técnica es una variable histórica"):

En realidad, la superstición recurre únicamente a medios falsos para satisfacer una necesidad verdadera y, por ello, ni esta digna de condena como a veces se piensa, ni resulta extraña a los así llamados siglos ilustrados, ni a los hombres ilustrados.

Pues quien puede decir que satisface siempre sus necesidades fundamentales de manera pura, correcta, completa y sin tacha: o que junto con la actividad y los logros más serios, como la fe y la esperanza, no busca consuelo también en la superstición, y la ilusión, la frivolidad y el prejuicio (Warburg, 2015: 490).

Como el ritual, una imagen tiene por fin producir una creencia (creer que la vida es posible): "La representación (performance) puede ser o bien "hacer-creencia" o bien "hacer-creer"' (Schechner, 2012: $60)^{2}$. Un ritual (una imagen) que no es capaz de producir una tal creencia, un conjunto de reglas (imágenes) que no sirve ni para modificar un estado de cosas ni para transformar el estatuto de los agentes involucrados en él, se mostrará ineficaz y será así tenido por inútil y no asegurará ningún control social sobre los agentes involucrados. En este sentido, la economía de la Pathosformel, implica que la imagen, a través de las sucesivas trasformaciones, inversiones de sentido y actualizaciones, sea portadora de un acto de creencia: una imagen que no produce tal creencia será una mera ilustración, no será parte del acto fundamental por el cual se abre una distancia interponiéndose entre nosotros y el mundo y, finalmente, será olvidada y descartada del suelo de la cultura. En este sentido, el orden de la veridicción (Foucault, 1994) impuesto por la economía de los rituales y de las imágenes no se centra en la distinción entre verdadero/falso sino en torno al par eficaz/ineficaz. Por ello la imagen no traduce una experiencia original que desde el pasado debería permanecer, retener y conservar: ella hace presente una memoria intensiva (Ruiz, 2013) que nos exige actuar. La ausencia de imagen hace aparecer el vacío del que nos debemos distanciar: 
En este punto puede resultar oportuna la historia de la rueda de la carreta de Lao-tsé: los radios de la rueda y el cubo (esto es, el bloque central de la rueda que sujeta el eje y los radios) al que van unidos no valdrían para nada dijo Lao-tsé, si no fuera por el agujero, el hueco, el vacío del centro. La communitas, con su carácter desestructurado, que representa lo "inmediato" de la interacción humana (...) podría muy bien compararse con 'el vacío del centro', que es indispensable, sin embargo, para el funcionamiento de la rueda (Turner, 1988: 133).

A partir de los diálogos compartidos con Richard Schechner, Víctor Turner elabora un concepto de proceso ritual que, a través de la noción de drama, le permite descomponerlos según fases que definen diferentes momentos de pasaje (Van Gennep, 2013). En tanto que dramas, los procesos rituales se inician siempre por una ruptura - una brecha - en el orden de las creencias establecidas; a esta primera fase le seguirán otras tendientes a restablecer la unidad estructurada de la sociedad (en este sentido, la función del ritual es restaurar un orden perdido). En estas fases, la liminaridad será esencial porque muestra que, por detrás de aquellas reglas - en la brecha que inaugura el drama - se aparece una communitas que señala hacia una indiferenciación con relación a toda norma o jerarquización social (finalmente, el drama será resuelto por la asunción de nuevas reglas que restablecen el orden perdido) ${ }^{3}$.

Esta abertura hacia un estado de indiferenciación tiene, en Turner, diversas explicaciones y se aplica a diversos niveles: desde uno estrictamente ontológico (en que la communitas sería, en última instancia, indiferenciación de lo existente) hasta una de grado más bien "sociológico" (en que la communitas es un estadio en que, temporalmente, se han suspendido las pautas de organización social). En todo caso, la liminaridad impone una temporalidad que excede la forma lineal de las narraciones habituales: "La communitas pertenece al ahora, mientras que la estructura se haya enraizada en el pasado y se proyecta al futuro a través de la ley y la costumbre" (Turner, 1988:119, subrayado nuestro). El carácter especial de esta abertura al ahora vacío de la communitas resulta para nuestros intereses fundamental, ya que implica una puesta en suspenso de los elementos que jerarquizan las relaciones sociales y muestran la presencia entre nosotros de un vínculo que la comunidad no puede dejar de expulsar fuera de sí:

La communitas se introduce por los intersticios de la estructura en el caso de la liminaridad; por los márgenes en el caso de la marginalidad; y por debajo suyo, si se trata de la inferioridad. No existe prácticamente lugar alguno en que no se considere sagrada 0 'santa', y ello quizá, porque transgrede o elimina las normas que rigen las relaciones estructuradas e institucionalizadas, al tiempo que va acompañada de una fuerza sin precedentes (Turner,1988: 134 subrayado nuestro).

Esta fuerza de la communitas le hace pensar a Turner en una posible apertura de lo social a través de la moral abierta, la religión y el arte, en el mismo sentido que ya lo hiciera Bergson en Las dos fuentes de la moral y la religión:

La communitas tiene también un aspecto de potencialidad, de ahí que se dé frecuentemente en el modo subjuntivo. Las relaciones entre seres totales son generadoras de símbolos, metáforas y comparaciones; sus productos son el arte y la religión más que las estructuras políticas y legales. Bergson vio en las palabras y escritos de los profetas y grandes artistas la creación de una "moralidad abierta", que era a su vez expresión de lo que él llamaba l'élan vital, o impulso vital evolutivo (Turner, 1988:133 subrayado nuestro).

Como vemos, a través del vacío que se abre con la fuerza de la liminaridad, se inaugura un umbral por el que la comunidad se descubre a sí misma condicionada por una serie de normas y reglas que la 
experiencia del arte viene a revelar. Las imágenes, así, restauran la existencia y, sin embargo, ellas también nos hacen mirar el vacío (la rueda de Lao Tsé, según lo explicara Turner) sin la cual nada podría funcionar: es la existencia liminar que la imagen a la vez indica y oculta. Es en el mismo sentido que Warburg hace de las imágenes una experiencia liminar: ellas no vienen a restaurar un orden perdido. Más bien mantienen la tensión liminar por la que el espacio del pensamiento se abre a su propia posibilidad trayendo la memoria de aquel vacío que la propia imagen viene a ocutlar. De hecho, cancelar ese espacio, cerrar la liminaridad que la imagen presenta, supone un cierre del espacio del pensar (sea por un exceso de la magia - teocracia - o por un exceso de la técnica - tecnocracia - que conduce en ambos casos a formas del autoritarismo. Así lo expone en el famoso final de El ritual de la serpiente:

El telégrafo y el teléfono destruyen el cosmos. El pensamiento mítico y simbólico, en su esfuerzo por espiritualizar la conexión entre el ser humano y el mundo circundante, hace del espacio la zona de contemplación o de pensamiento que la electricidad hace desaparecer mediante una conexión fugaz (Warburg, 2004: 66)

La cultura vive y sobrevive en y a través de un ritual de imágenes. Nuestro devenir tecno informático exige que podamos, para evitar sus excesos autoritarios del presente, encontrar las imágenes que devuelvan el equilibrio indispensable para la existencia. No sabemos si esas imágenes nos llegarán desde los restos de los demonios astrales de la Antigüedad. O si nos llegarán de nuevas formas que las serpientes puedan ofrecernos (enrolladas como estaban en los proyectores del cine). 0 si deberemos inventarnos imágenes que vuelvan a abrir el espacio liminar indispensable para un Denkraum. Pero sí sabemos que sin esos rituales de imágenes (que nos hacen comunidad) nos asomaremos, de forma inevitable al vacío de la rueda, al espanto de la muerte que ninguna fórmula algorítmica puede explicar. Por ello, a riesgo de tener que luego rectificarnos podríamos decir que el arte es una forma ritual de las imágenes. Y que la iconología intenta determinar los pasajes, los ritos de pasajes, a través de los que las imágenes organizan y orientan nuestras vidas. Esas vidas que hoy se encuentras técnicamente vaciadas por los cálculos infinitos de una máquina digital que no nos deja imaginar.

\section{Referencias}

BENJAMIN, Walter. Pequeña historia de la fotografía. In: Discursos interrumpidos $I$. España: Taurus. 1989.

Calle de mano única. Buenos Aires, El cuenco de plata, 2014.

DELEUZE, Gilles, Qu'est-ce que l'acte de création. In Deux régimes de fous. France: Minuit, 2003.

DIDI-HUBERMAN, Georges. Ante el tiempo. Buenos Aires: Adriana Hidalgo, 2006.

A semelhança informe ou o gaio saber visual segundo Georges Bataille. Rio de Janeiro: Contraponto, 2015.
FOUCAULT, Michel. Les mots et les images. In: Dits et Ecrits I. Paris: Gallimard, 1994.

Cómo nace un "libro experiencia". In: El yo minimalista y otras conversaciones. Buenos Aires: Biblioteca de la Mirada, 1996.

LE BRETÓN, David. Antropologia dos sentidos. Petrópolis: Editora Vozes, 2016.

MAUSS, Marcel, Sociología y antropología. Madrid: Tecnos, 1979.

RUIZ, Raúl. Poéticas del cine. Santiago de Chile: Universidad Diego Portales, 2013. 
SCHECHNER, Richard Estudios de representación. Una introducción. México: FCE, 2012.

TURNER, Víctor. El proceso ritual. Estructura y antiestructura. Madrid: Taurus, 1988.

ULM, H. La curación infinta: el arte y la estética más allá de las cuestiones del gusto; en AAVV, Ese Nietzsche. Salta: Ediciones de la galeria Fedro, 2014, p. 113-142.
VAN GENNEP, Arnold. Los ritos de paso. Madrid: Alianza, 2013.

WARBURG, Aby. El ritual de la serpiente. Ciudad de México: Sexto Piso, 2004. . Atlas, Madrid: Akal, 2010.

- El renacimiento del paganismo. Aportaciones a la historia cultural del Renacimiento europeo. Madrid: Alianza, 2015.

\title{
Notas
}

\begin{abstract}
" Professor de Estética e Historia del Arte en la Universidad Nacional de Salta, Argentina. E-mail: <hernanulm@gmail.com>. ORCID: < https://orcid.org/0000-0003-0387-6270>.

${ }^{1}$ Resulta extraño leer la reseña de Foucault a la traducción de Ensayos de iconología y de Arquitectura gótica y pensamiento medieval. Al leer ese artículo, parece que el filósofo francés adivina en el discípulo de Warburg la presencia de un pensador que Panofsky se ha esmerado en borrar: "El discurso no es el fondo interpretativo común a todos los fenómenos de una cultura. Hacer aparecer una forma, no es una manera desviada (más sutil o más ingenua, como se quiera) de decir algo. Todo lo que hacen los hombres no es, al fin de cuenta, un murmullo indescifrable. El discurso y la figura tienen cada uno su modo de ser; pero mantienen relaciones complejas y encabalgadas. Es su funcionamiento recíproco lo que se trata de describir" (Foucault, 1994: 622, traducción nuestra).

${ }^{2}$ El título en inglés del libro de Richard Schechner es Performance Studies. An introduction. Los traductores de la versión española han optado por la palabra "representación" en vez de "performance" lo que lleva, a nuestro parecer, a ciertos equívocos, ya que "performance" supone elementos que están ausentes de "representación" y, en primer lugar, el aspecto ritual de las acciones que se producen (por no mencionar que, en español, el vocablo sugiere una "representación mental" que está ausente de la cuestión planteada por Schechner). El vocablo "performance", además, es lo suficientemente difundido en nuestro idioma como para exigir una traducción. Finalmente, como se verá enseguida, Schechner, en diálogo estrecho con Turner, establece un lazo indisoluble entre la experiencia ritual y la performance.

3 Turner (1988) diferencia la comunidad (como organización social jerarquizada) de la "communitas" en la que todas las jerarquías son puestas, al menos transitoriamente, en suspenso para abrir el juego del vacío social en el que aparece una indiferencia ontológica.
\end{abstract}

Artigo recebido em maio de 2020. Aprovado em julho de 2020. 